\title{
Serum iron and iron kinetics in coalworkers with complicated pneumoconiosis
}

\author{
B. W. B. CHAN 1 \\ Medical Research Council Pneumoconiosis Research Unit, Llandough Hospital, Penarth, Glam.
}

\begin{abstract}
Chan, B. W. B. (1969). Brit. J. industr. Med., 26, 65-70. Serum iron and iron kinetics in coalworkers with complicated pneumoconiosis. Twenty-three patients with complicated pneumoconiosis were studied, and compared with 16 patients of similar age with chronic non-specific lung disease. In seropositive cases (Rose Waaler titre higher than $1: 32$ ) the serum iron, total iron binding capacity (T.I.B.C.), and the serum iron/T.I.B.C. \% were all significantly decreased. In seronegative cases only the T.I.B.C. was significantly decreased.

Low serum iron levels were found to be associated with a high iron clearance rate, so that the total iron transport rate was normal or slightly increased. The proportion of circulating plasma iron utilized for effective red cell production was found to be normal.

These findings are, in general, similar to those in rheumatoid arthritis and suggest that iron mobilization or transport may be defective but that erythropoiesis is not depressed.
\end{abstract}

Iron is transported in the plasma in combination with a plasma protein, transferrin. Most of this iron is on its way to the bone marrow to be used for haemoglobin synthesis and will eventually appear in circulating red cells. Characteristic patterns of change in the serum iron levels and the total iron binding capacity (T.I.B.C.) are found in conditions in which the mechanisms of plasma iron transport and utilization for haemoglobin synthesis are deranged (Bothwell and Finch, 1962).

Anaemia is common in coalworker's pneumoconiosis. In a large-scale survey of the population of the Rhondda Valley (Kilpatrick and Hardisty, 1961) it was found that when the data on miners and ex-miners were further analysed according to the $x$-ray category of pneumoconiosis, those with complicated pneumoconiosis had consistently lower haemoglobin and serum iron levels compared with the mean for their age groups (Kilpatrick, personal communication, 1967). At the Medical Research Council Pneumoconiosis Research Unit over the past two years, the serum iron levels have also frequently been observed to be low in patients

${ }^{1}$ Present address: Department of Medicine, University of Cambridge. suffering from complicated pneumoconiosis. These findings, however, are difficult to interpret without further studies of both the T.I.B.C. and the more dynamic aspects of plasma iron transport. In particular, they pose the questions, whether the pattern of change may be interpreted as one of iron deficiency or whether a defect in the mechanisms of transport or utilization may be involved.

The present report is concerned with studies of (1) serum iron levels and iron binding capacities;

(2) plasma iron clearance and transport rates; and (3) utilization of plasma iron for effective erythropoiesis. The results of these studies in patients with complicated pneumoconiosis are compared with results in patients with chronic non-specific lung disease.

\section{Selection of subjects}

The 39 men were miners or ex-miners with chronic lung disease in a stable state at the time the tests were made. Patients with congestive cardiac failure, purulent sputum or acute exacerbation of bronchitis within the preceding month were excluded from the study. 
The patients were divided into the following groups:

Group 1 Complicated pneumoconiosis (23 patients) Patients were included in this group on the basis of radiological appearances of massive lesions in the lungs, and were further divided into two subgroups:

1a Seropositive group (11 patients) Patients were included in this group if the serum Rose Waaler titre was higher than $1: 32$ (actual range $1: 128$ $1: 4069)$. The radiological appearance of the chest ranged from that typical of rheumatoid pneumoconiosis (Caplan, 1953) to that of classical progressive massive fibrosis (P.M.F.) Eight of the patients had rheumatoid arthritis. The mean age of this group was 56.6 (range 45-69) years.

1b Seronegative group (12 patients) Patients were included in this group if the serum Rose Waaler titre was less than $1: 32$. None of the patients had arthritis. The mean age was $61 \cdot 4(54-68)$ years.

\section{Group 2 Chronic non-specific lung disease (16} patients)

This group consisted of patients with chronic obstructive lung disease with or without simple pneumoconiosis. The serum Rose Waaler titre was less than $1: 32$ in all cases. The mean age was $56 \cdot 7(43-68)$ years.

\section{Methods}

Serum iron and iron binding capacity were measured in all 39 patients. The methods used were those of Ramsay $(1957 a, b)$. In order to minimize errors due to the circadian variations of serum iron levels, all samples were taken between 2 and 3.30 p.m.

Plasma iron clearance and transport studies were made in 20 patients, eight in group $1 \mathrm{a}$ and six each in groups $1 \mathrm{~b}$ and 2. The method used was a modification of that of Huff, Tobias, and Lawrence (1952) in which 5-10 $\mu \mathrm{c}$. of ${ }^{59} \mathrm{Fe}$ in the form of high specific activity ferric citrate (approx. $5 \mu \mathrm{c} . / \mu \mathrm{g}$.) was injected intravenously. Six venous blood samples were obtained at approximately 20-minute intervals during the next two hours, and the radioactivity of the plasma was plotted against time on semilogarithmic paper. A satisfactory straight line plot was obtained in all cases and from it the half clearance time ( $\left.\mathrm{T}_{\frac{1}{2}}\right)$ was read off. All clearance experiments were made between 3 and 6 p.m. The clearance constant is the constant $k$ in the equation $Y_{t}=Y_{o} e^{-k t}$, where $Y_{o}$ and $Y_{t}$ are respectively the radioactivity of the plasma at the time of injection of ${ }^{59} \mathrm{Fe}$ and a given time $t$ following it, and expresses the proportion of plasma iron being removed in unit time. It is calculated by dividing the natural logarithm of 2 by the half clearance time in hours.

The plasma iron transport rate was calculated as the product of the clearance constant, the serum iron, and the plasma volume and expressed as milligrammes of iron transported per day per kilogramme bodyweight.
The plasma volume was calculated indirectly from the red cell volume which was measured by the ${ }^{51} \mathrm{Cr}$ method of Gray and Sterling (1950) as modified by Mollison and Veall (1955). A whole body: venous haematocrit ratio of 0.91 was assumed (Chaplin, Mollison, and Vetter, 1953).

The percentage of the ${ }^{59} \mathrm{Fe}$ dose utilized for effective erythropoiesis was calculated from the total dose injected, the red cell volume, and the ${ }^{59} \mathrm{Fe}$ content of red cells in a blood sample taken 13-15 days after injection. Radioactivity due to ${ }^{59} \mathrm{Fe}$ and ${ }^{51} \mathrm{Cr}$ was separated by gamma ray spectrometry.

Arterial blood was sampled from the brachial artery and analysed for oxygen saturation in a Unicam spectrophotometer by the method of Deibler, Holmes, Campbell, and Gans (1959).

\section{Results}

Mean values for serum iron, T.I.B.C., and serum iron/T.I.B.C. $\%$ for each group of patients are shown in Table 1. Differences in means between groups were analysed for significance by applying Student's ' $t$ ' test for small numbers.

In patients with chronic non-specific lung disease (group 2) the results were within the normal range for this laboratory.

When all patients with complicated pneumoconiosis were considered as a group, it was found that both the serum iron and the T.I.B.C. were significantly decreased but that there was no significant decrease in the serum iron/T.I.B.C. $\%$. However, the situation was markedly different in the two sub-groups. The seropositive group showed a significant decrease in serum iron, T.I.B.C., and serum iron/T.I.B.C. \%. The decrease in the serum iron was particularly marked, the mean value being only half that of group 2, whereas in the seronegative group the serum iron level was not significantly different from that of group 2 , neither was the serum iron/T.I.B.C \%, and only the T.I.B.C. was significantly decreased.

In the iron clearance and transport experiments, care was taken to exclude cases of secondary polycythaemia due to severe hypoxia, as this might be expected to influence iron metabolism. Arterial blood oxygen saturation was therefore measured in all but one patient studied. In all cases where this measurement was made, it was above $85 \%$. In the one patient on whom this was not done, there was minimal disturbance of lung function only, and he was therefore unlikely to have significantly decreased arterial blood oxygen saturation. Furthermore, the results presented here on plasma iron clearance and transport have been analysed for correlation with arterial blood oxygen saturation and, in all the groups studied, the coefficients of correlation between these variables were not significantly different from zero.

Clearance graphs showing rates of disappearance 
TABLE 1

Serum Iron, T.I.B.C., and Serum Iron/T.I.B.C. \% in Complicated Pneumoconiosis compared with Chronic Non-SPeCIfIC Lung Disease

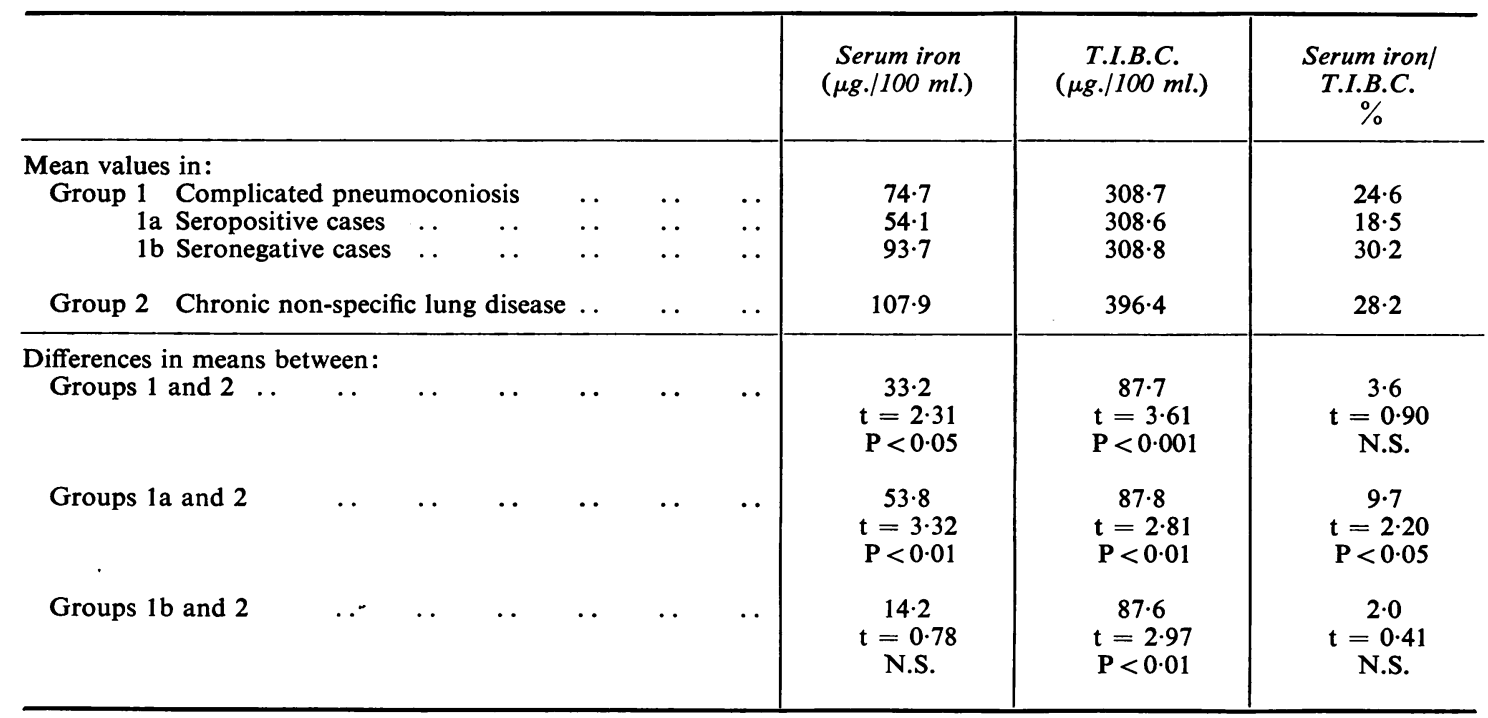

$\left(\mathrm{n}_{1 \mathrm{a}}=11, \mathrm{n}_{1 \mathrm{~b}}=12, \mathrm{n}_{2}=6\right)$

of injected ${ }^{59} \mathrm{Fe}$ in individual cases are shown in Figure 1. It is at once apparent that the seropositive cases have greatly increased rates of clearance compared with group 2, whereas the seronegative cases occupy an intermediate position. Expressing these clearance rates in terms of the clearance constant (Table 2), this was found to be raised for the whole group of patients with complicated pneumoconiosis, the increase being particularly marked in the seropositive group. In this group the
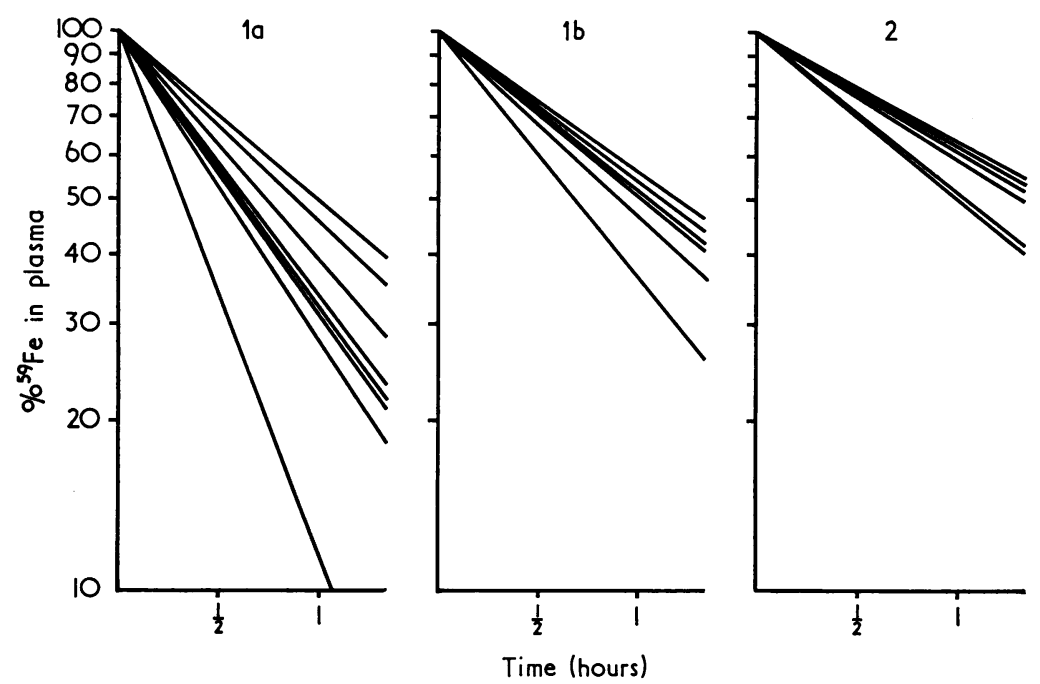

FIG. 1. Clearance graphs showing rates of disappearance of injected ${ }^{59} \mathrm{Fe}$ in individual cases. 1a. Complicated pneumoconiosis seropositive cases. 1b. Complicated pneumoconiosis sero-negative cases. 2. Chronic non-specific lung disease. 
TABLE 2

Plasma Iron Clearance and Transport in Complicated Pneumoconiosis compared with Chronic Non-SPECIFIC LUNG Disease

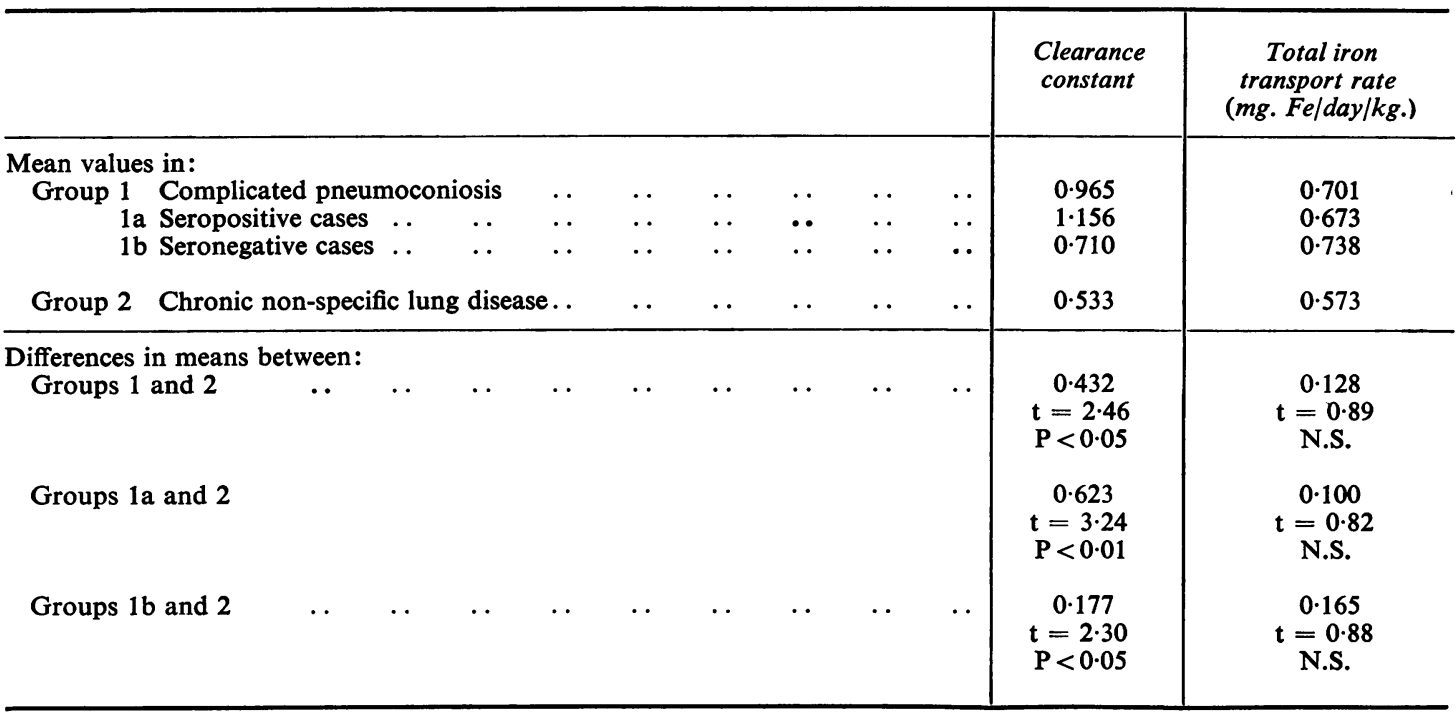

$\left(n_{1 \mathrm{a}}=8, \mathrm{n}_{1 \mathrm{~b}}=6, \mathrm{n}_{\mathrm{2}}=6\right)$

clearance constant was more than twice the normal value.

However, when the results of these experiments were expressed in terms of the total iron transport rate, thus taking into account the serum iron levels, no significant difference was found between the groups. In fact, the total iron transport rate was slightly (but not significantly) higher in complicated pneumoconiosis, thus the increase in iron clearance rate more than adequately accounted for the reduced serum iron levels in these patients. This relationship between serum iron levels and iron clearance is further shown in Fig. 2, in which half clearance times are plotted against serum iron levels. A highly

TABLE 3

Percentage Dose of Radio-Iron utilized for Effective Red Cell Production

\begin{tabular}{l|c|c}
\hline \multicolumn{1}{c|}{ Description of subjects } & $\begin{array}{c}\text { No. of } \\
\text { subjects }\end{array}$ & $\begin{array}{c}\%{ }^{\circ} \mathrm{Fe} \\
\text { utilized for } \\
\text { R.B.C.s }\end{array}$ \\
\hline Complicated pneumoconiosis & 8 & $\begin{array}{c}84 \cdot 8 \\
(75 \cdot 5-97 \cdot 3) \\
71 \cdot 9 \\
(65 \cdot 4-77 \cdot 6) \\
70-90\end{array}$ \\
Chronic non-specific lung disease & 3 & $\begin{array}{c}70-9 \\
\text { Normal range }\end{array}$ \\
\hline
\end{tabular}

(Normal values from Bothwell and Finch (1962) Iron Metabolism, Churchill, London.)

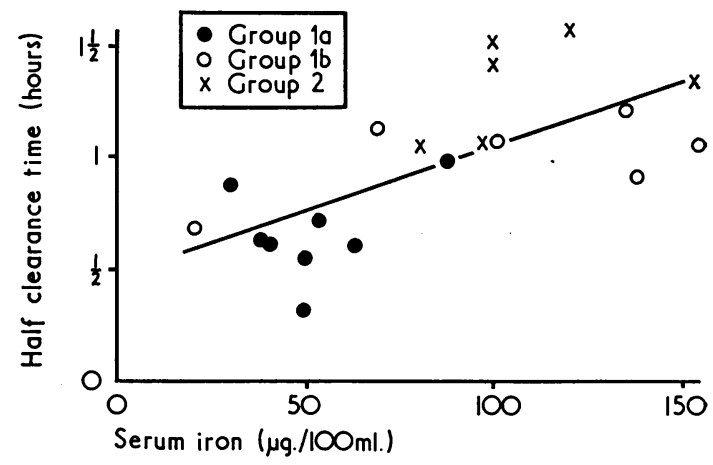

FIG. 2. Correlation between serum iron levels and half clearance time.

significant correlation was found between these two variables $(r=0.68, P<0.001)$.

Table 3 shows the results of experiments measuring the percentage dose of radio-iron utilized for effective erythropoiesis. The number of experiments was small and the results have not been subjected to statistical analysis. However, it is apparent that the percentage utilization was not reduced in cases of complicated pneumoconiosis. In all eight cases studied, it lay within or above the normal range and the mean value was higher than in the three cases of chronic non-specific lung disease studied. 


\section{Discussion}

Caplan (1953) first drew attention to the association between complicated pneumoconiosis, often with a characteristic radiological appearance, and rheumatoid arthritis. Recent work by Wagner and McCormick (personal communication) using immunofluorescence and other techniques also tended to support the view that some cases of complicated pneumoconiosis, with or without rheumatoid arthritis, had a background of immunological disturbance. Clinical manifestations of rheumatoid arthritis were very variable in the patients studied in the present series. In the seropositive group, arthritis of moderate severity was present in only three patients, minor symptoms and signs were present in a further five patients, while the remaining three patients had no arthritis at all. Although there is no direct evidence that the changes reported in this paper were due to an immunological abnormality, it is interesting to note that the changes were much more marked in the group exhibiting a positive serum rheumatoid factor. It seemed therefore appropriate to discuss these findings in relation to similar changes in rheumatoid arthritis.

\section{Serum iron and T.I.B.C.}

The considerable amount of data on changes in these parameters in various disease states has been reviewed by Bothwell and Finch (1962). Although it might be supposed from the finding of low serum iron levels that iron deficiency is common in coalworker's pneumoconiosis, the reduction in T.I.B.C. contrasts sharply with the situation in iron deficiency, in which the T.I.B.C. is consistently and often markedly elevated.

Iron metabolism and other haematological aspects of rheumatoid arthritis have been reviewed by Pitcher (1966). The situation is complex. True iron deficiency undoubtedly occurs in a minority of patients. The factors involved include gastrointestinal tract bleeding as a result of corticosteroid and salicylate therapy, and the fact that many female patients belong to an age group in which iron deficiency is common. Defective iron absorption has also been suggested (Roberts, Hagedorn, Slocumb, and Owen, 1963). However, there remains a large group of patients in whom the low serum iron levels cannot be attributed to iron deficiency. Richmond, Gardner, Roy, and Duthie (1956) found that tissue iron stores were frequently normal or increased in the presence of low serum iron levels. In general, the reduction in serum iron levels appears to be related to the activity of the rheumatoid process and the T.I.B.C. is normal or slightly decreased. This is a situation similar to the present findings in complicated pneumoconiosis. The basic abnormality may well be a failure to mobilize tissue iron or a failure for plasma transferrin to bind the iron that is available, rather than a simple iron deficiency.

\section{Iron clearance, transport, and utilization}

The increased plasma iron clearance rates in the presence of low serum iron levels may be interpreted as a compensatory phenomenon, ensuring a normal supply of iron to haemopoietic tissues. This finding, together with the normal percentage dose of injected radio-iron appearing in circulating red cells, clearly indicates that the red cell precursors are well able to utilize iron that reaches them fully bound to plasma transferrin. Erythropoiesis, as judged by the results of these experiments, is normal or slightly increased in cases of complicated pneumoconiosis. Similar findings have been reported in rheumatoid arthritis (Freireich, Ross, Bayles, Emerson, and Finch, 1957; Weinstein, 1959).

\section{Conclusions}

It seems reasonable to conclude that complicated pneumoconiosis is associated with an abnormal pattern of iron metabolism. Despite low serum iron levels the pattern is not typical of iron deficiency and may possibly indicate abnormal binding by plasma proteins or abnormal mechanisms of mobilization of tissue iron. Utilization of iron for erythropoiesis is not depressed. These changes are much more marked in cases exhibiting a positive serum rheumatoid factor. The findings provide further evidence of the systemic nature of the disturbance in some cases of coalworker's pneumoconiosis and may have relevance within the context of the modern views of the pathogenesis of this disease.

I wish to thank Mr. R. A. Saunders and his staff, of the Biochemistry Department, Llandough Hospital, for making the serum iron and T.I.B.C. measurements.

\section{References}

Bothwell, T. H., and Finch, C. A. (1962). Plasma transferrin and its iron. In Iron Metabolism. pp. 138-179. Churchill, London.

Caplan, A. (1953). Certain unusual radiological appearances in the chest of coal-miners suffering from rheumatoid arthritis. Thorax, 8 , 29.

Chaplin, H., Jr., Mollison, P. L., and Vetter H. (1953). The body/ venous hematocrit ratio: its constancy over a wide hematocrit range. J. clin. Invest., 32, 1309.

Deibler, G. E., Holmes, M. S., Campbell, P. L., and Gans, J. (1959). Use of Triton-X 100 as a hemolytic agent in the spectrophotometric measurement of blood $\mathrm{O}_{2}$ saturation. J. appl physiol., 14, 133.

Freireich, E. J., Ross, J. F., Bayles, T. B., Emerson, C. P., and Finch, S. C. (1957). Radioactive iron metabolism and erythrocyte survival studies of the mechanism of the anemia associated with rheumatoid arthritis. J. clin. Invest., 36, 1043.

Gray, S. J., and Sterling, K. (1950). Determination of circulating red cell volume by radioactive chromium. Science, 112, 179.

Huff, R. L., Tobias, C. A., and Lawrence, J. H. (1952). A test for red cell production. Acta haemat. (Basel), 7, 129.

Kilpatrick, G. S., and Hardisty, R. M. (1961). The prevalence of anaemia in the community. Brit med.J., $1,778$. 
Mollison, P. L., and Veall, N. (1955). The use of the isotope ${ }^{51} \mathrm{Cr}$ as a label for red cells. Brit.J. Haemat., 1, 62.

Pitcher, C. S. (1966). Anaemia in rheumatoid arthritis. In Hill, A. G. S. (Ed.). Modern Trends in Rheumatology, pp. 139-152. Butterworths, London.

Ramsay, W. N. M. (1957a). The determination of iron in blood plasma or serum. Clin. chim. Acta, 2, 214.

- (1957b). The determination of the total iron-binding capacity of serum. Ibid., 2, 221.
Richmond, J., Gardner, D. L., Roy, L. M. H., and Duthie, J. J. R. (1956). Nature of anaemia in rheumatoid arthritis. III. Changes in the bone marrow and their relation to other features of the disease. Ann. rheum. Dis., 15, 217.

Ann. rheum. Dis., 15, 217.
Roberts, F. D., Hagedorn, A. B., Slocumb, C. H., and Owen, C. A. (1963). Evaluation of the anemia of rheumatoid arthritis. Blood, 21, 470.

Weinstein, I. M. (1959). A correlative study of the erythrokinetics and disturbances of iron metabolism associated with the anemia of rheumatoid arthritis. Ibid., 14, 950.

\section{The October (1968) Issue}

Dental Erosion in Industry H. J. Ten Bruggen Cate

Bagassosis: an Epidemiological, Environmental, and Clinical Survey C. E. D. HeARN

Immunological Aspects of Bagassosis C. E. D. HeArn and VALERIE Holford-Strevens

Mortality from Lung Cancer and Other Causes among Workers in an Asbestos Textile Factory J. F. KNox, S. Holmes, R. Doll, and I. D. Hill

Toxicity of Paraquat and Diquat Aerosols Generated by a Size-selective Cyclone: Effect of Particle Size Distribution J. C. GAGE

Uptake of Mercury by the Brain L. MAGos

Allergenicity of Piperazine: A Study in Environmental Aetiology. S. F. McCullagh

Notes and Miscellanea

Incidence of Boxing Injuries in the Royal Air Force in the United Kingdom 1953-66 T. N. N. BrenNAN and P. J. O'CONNOR

Book Reviews

Index

A number of copies are still available and may be obtained from the Publishing Manager, British Medical Association, Tavistock Square, London W.C.1, price 18s. 6 d. 